\title{
BINGE DRINKING AND DECLARATIVE MEMORY IN UNIVERSITY STUDENTS
}

María Parada, Montserrat Corral, Francisco Caamaño-Isorna, Nayara Mota, Alberto Crego, Socorro Rodríguez Holguín, and Fernando Cadaveira

This is the peer reviewed version of the following article: Parada M; Corral M; Caamaño-Isorna F; Mota N; Crego A; Rodríguez Holguín S; Cadaveira F. (2011). Binge drinking and declarative Memory in University students. Alcoholism: Clinical and Experimental Research, 35, 81475-1484, which has been published in final form at https://doi.org/10.1111/j.1530-0277.2011.01484.x. This article may be used for non-commercial purposes in accordance with Wiley Terms and Conditions for Use of Self-Archived Versions 


\section{Binge Drinking and Declarative Memory in University Students}

María Parada, Montserrat Corral, Francisco Caamaño-Isorna, Nayara Mota, Alberto Crego, Socorro Rodríguez Holguín, and Fernando Cadaveira

Departamento de Psicoloxía Clínica e Psicobioloxía (MP, MC, NM, AC, SRH, FC) and Departamento de Medicina Preventiva e Saúde Pública (FC-I), Universidade de Santiago de Compostela, Santiago de Compostela, Spain.

Corresponding author: María Parada, Departamento de Psicoloxía Clínica e Psicobioloxía, Facultade de Psicoloxía, Xosé Suárez Núñez s / n Campus Sur, Universidade de Santiago de Compostela 15782, Santiago de Compostela, España; Tel.: +34 981 563100; Fax: +34 981 528071; E-mail: maria.parada@usc.es 


\begin{abstract}
Background: Binge drinking (BD), which is characterized by sporadic consumption of large quantities of alcohol in short periods, is prevalent among university students. Animal studies have shown that $\mathrm{BD}$ is associated with damage to the hippocampus, a region of the brain that plays a key role in learning and memory. The temporal cortex undergoes structural and functional changes during adolescence. The aim of the present study was to examine the association between BD and declarative memory in male and female university students. Methods: The participants were 122 students (between 18 and 20 years of age): 62 BD (30 women) and 60 non-BD (29 women). The neuropsychological assessment included the Rey Auditory Verbal Learning Test (RAVLT) and Weschler Memory Scale-3rd ed. (WMS-III) Logical Memory subtest, to evaluate verbal declarative memory, and the WMS-III Family Pictures subtest, to measure visual declarative memory. Results: The BD students remembered fewer words in the interference list and displayed greater proactive interference in the RAVLT; they performed worse in the Logical Memory subtest, both on immediate and delayed recall. There were no differences between the groups in performance of the Family Pictures subtest. No significant interactions were observed between BD and sex. Conclusions: Binge drinking is associated with poorer verbal declarative memory, regardless of sex. The findings are consistent with the vulnerability of the adolescent hippocampus to the neurotoxic effects of alcohol. Longitudinal studies will help determine the nature of this relationship, the neurodevelopmental trajectories for each sex, and the repercussions on academic performance.
\end{abstract}

\title{
Key Words
}

Binge drinking, University students, Episodic declarative memory, Hippocampus, Sex differences. 


\section{Introduction}

Binge drinking (BD) is characterized by sporadic consumption of large quantities of alcohol in short periods. It is usually defined as the consumption of 5 or more alcoholic drinks (4 or more in the case of women) on a single occasion (within 2 hours, according to the National Institute on Alcohol Abuse and Alcoholism), at least once in the previous 2 weeks / 1 month (Courtney and Polich, 2009). Epidemiological studies have noted a high prevalence of this pattern of consumption among adolescents and young adults, especially university students (Anderson, 2007; Hibell et al., 2004; Kypri et al., 2009; O’Malley et al., 1984; Wechsler et al., 2002; White et al., 2006). In the U.S.A., the prevalence of BD among young people is so high (around 40\%) that this pattern of consumption and its consequences are now considered one of the most important health problems in the country (Department of Health and Human Services, 2002; Wechsler et al., 2002). Although the phenomenon has been less well studied in Europe, it has been reported that $24 \%$ of young adults between 15 and 24 years old show a BD pattern of alcohol consumption (Eurobarometer, 2007), and that there has been an increase $(2 \%)$ in the prevalence of BD in the past 10 years (Anderson, 2007). In Spain, in a sample of 2,700 university students between 18 and 19 years old, 12.2\% exhibited a BD pattern, with a prevalence of $8.7 \% 2$ years later (Caamañ o-Isorna et al., 2008; Mota et al., 2010).

Despite this frequent pattern of alcohol consumption among teenagers and young adults, the effect of BD on adolescent neurodevelopment and brain functioning is still unclear. During adolescence, understood to be the period spanning the second decade of life, important structural and functional changes take place in the nervous system, especially in the prefrontal cortex and the mesolimbic regions (Crews et al., 2007; Lenroot and Giedd, 2006; Spear, 2000; Yurgelun-Todd, 2007). In addition, animal studies with rats have demonstrated that the adolescent brain is more vulnerable to the neurotoxic effects of alcohol than the adult brain (Guerri and Pascual, 2010; White and Swartzwelder, 2005). One structure that appears particularly sensitive to the neurotoxic effects during adolescence is the hippocampus (Chin et al., 2010; White and Swartzwelder, 2004, 2005), a region that plays an important role in learning and declarative memory (Burgess et al., 2002; Eichenbaum, 1999; Teyler and Rudy, 2007; Van Petten, 2004). A study on adolescent nonhuman primates has provided evidence of a neurotoxic effect of intensive consumption of alcohol on neurogenesis of the hippocampus (Taffe et al., 2010). Also, alcohol inhibits the induction of longterm potentiation and N-Methyl-d-Aspartate (NMDA) receptor-mediated synaptic potential more potently in the hippocampus of adolescent rats than in that of adult rats ( $\mathrm{Li}$ et al., 2002; Pyapali et 
al., 1999; Swartzwelder et al., 1995a,b). Similarly, although some studies have shown contrary results (Schulteis et al., 2008; White et al., 2000), adolescent rats subjected to a BD pattern of alcohol consumption displayed increased cell death in the neocortex, hippocampus, and cerebellum, and long-lasting difficulties in learning and memory relative to adult rats subjected to the same BD pattern (Pascual et al., 2007). The lack of consensus between the different studies may be because of methodological differences (in, e.g., ethanol exposure, test paradigm, data analysis strategies) (Chin et al., 2010).

In humans, adolescents with alcohol use disorders (AUD) have a smaller hippocampal volume than healthy subjects (De Bellis et al., 2000; Medina et al., 2007; Nagel et al., 2005), and greater differences are observed in the left hemisphere (Medina et al., 2007; Nagel et al., 2005). Moreover, BD subjects also perform less well in neuropsychological tasks that assess verbal and visuospatial declarative memory than healthy controls (Brown et al., 2000; Sher et al., 1997; Tapert and Brown, 1999; Tapert et al., 2002).

To date, very few studies with human adolescents have investigated the effects of the BD pattern on declarative memory (Garcí a-Moreno et al., 2008, 2009; Hartley et al., 2004; Schweinsburg et al., 2010). Hartley and colleagues (2004) compared the neuropsychological performance of 27 university students (aged 18 to 23 years) distributed in 2 groups according to their patterns of alcohol consumption: 14 binge drinkers (5 women with a consumption of 10 or more alcoholic drinks on a single occasion), and 13 abstainers (7 women who did not consume alcohol). The authors reported that BD students performed modestly lower than the abstainers $(p=0.08)$ in the delayed recall of a visual memory task (in which they were asked to recall a series of 20 drawings after a period of 25 minutes). The performance was similar in men and women binge drinkers. There were no differences in performance of a word-learning task (in which subjects were required to recall terms from a list of 36 words 25 minutes after their presentation).

García-Moreno and colleagues (2008, 2009) assessed university students (aged 18 to 20 years) distributed in 3 groups: abstainers; moderate consumers of 4 or less alcoholic drinks on a single night; and abusive consumers who drank 5 or more drinks on a single night. Moderate and abusive consumers performed significantly less well in a word-learning test than those who did not consume alcohol. The authors attributed these differences to difficulties in execution rather than memory, because the performance was characterized by higher numbers of perseverations, intrusions, and false positive. Conversely, there were no differences between the groups in a visuospatial memory task (Benton Visual Retention Test). 
Schweinsburg and colleagues (2010) conducted a functional MRI study to determine whether there were any differences between 12 high school binge drinkers (10 men) and 12 (4 women) demographically similar nondrinkers (aged 16 to 18 years). The authors reported that in comparison with non-drinkers, binge drinkers ( 5 or more drinks per occasion, 4 or more for women) displayed greater responses in frontal and parietal regions, no hippocampal activation to novel word pairs, and lower recall. The authors interpreted these results as possibly indicating greater reliance on alternate memory systems (working memory) during verbal learning and subtle consolidation dysfunction. Because the task used in the study was relatively easy, the authors recommended the use of more difficult tasks, such as a verbal list-learning task.

Given the scarcity of existing studies, the aim of the present study was to determine the association between the $\mathrm{BD}$ pattern of drinking and verbal and visual declarative memory. Because of the vulnerability of the adolescent hippocampus to the neurotoxic effects of alcohol, observed in studies with rats and monkeys (Chin et al., 2010; Taffe et al., 2010; White and Swartzwelder, 2004, 2005), we hypothesized that BD students will perform less well in declarative memory tasks than non-BD students. Second, we also explored whether the association between BD and memory is modulated by gender. The issue of increased vulnerability of women to the neurotoxic effects of alcohol is still controversial (for a review, see Oscar-Berman and Marinkovic, 2007). Several studies have reported sex differences in the effects of alcohol in alcoholics (Acker, 1986; Mann et al., 2005), AUD adolescents (Caldwell et al., 2005; Medina et al., 2008), and social drinkers (Scaife and Duka, 2009; Townshend and Duka, 2005; Weissenborn and Duka, 2003). However, other studies in alcoholics and healthy adults did not find any such differences (Glenn and Parsons, 1992; Yonker et al., 2005). Based on studies in adolescent clinical samples, we hypothesized BD women will perform less well than BD men on neuropsychological tests.

\section{Materials and Methods}

\section{Sample}

As part of an epidemiological study on alcohol BD, an anonymous survey was conducted among freshmen at the University of Santiago (Caamaño-Isorna et al., 2008). The questionnaire included the Galician version of Alcohol Use Disorders Identification Test (AUDIT) (Varela et al., 2005) and questions related to the use of alcohol (speed of consumption, age of onset on alcohol 
consumption, etc.). From the data obtained, students were classified as BD or non-BD. The classification criteria, as outlined in Crego and colleagues (2010), are based on the responses to 2 questions: the third question of the AUDIT (How often do you have 6 or more drinks on a single occasion? Never/Less than monthly/Weekly/Daily or almost daily) and 1 question pertaining to the speed of consumption (drinks per hour). Taking into account the differences in the amount of alcohol in 1 Standard Alcoholic Drink (SAD) in each country (International Center for Alcohol Policies, 2003), the criteria must be adjusted to the location of the investigation. In Spain, 1 SAD contains $10 \mathrm{~g}$ of alcohol, so that the BD group was formed by those who consumed 6 or more alcoholic drinks on a single occasion 1 or more times per month and drank 3 or more drinks per hour; the non-BD group was composed of those students who consumed less than this amount.

Once classified on the basis of alcohol consumption, those students who had stated that they would be willing to participate in the study, by providing contact information at the end of the questionnaire, were contacted by telephone or e-mail and invited to a preliminary interview with the aim of selecting the sample. A total of 305 students attended the interview (160 BD and 145 non$\mathrm{BD})$.

In the semi-structured interview, information about each student's medical history and personal and family psychopathology was collected. The interview comprised a translated and adapted version of the Semi-Structured Assessment for the Genetics of Alcoholism, Individual Assessment Module, and Family History Assessment Module, designed by the Collaborative Study on the Genetics of Alcoholism (Bucholz et al., 1994). Questions about individual and family psychopathological problems were based on Diagnostic and Statistical Manual of Mental Disorders-IV (DSM-IV) criteria and at least 1 other diagnostic classification system. The Symptoms Checklist-90-Revised questionnaire (SCL-90-R) (Degoratis, 1983) was also used to detect any psychopathological symptoms. Alcohol abuse/dependence was assessed in all subjects, by use of the AUDIT. The original AUDIT has been validated to assess alcohol-related problems or disorders (Allen et al., 1997; Babor et al., 2001; Conigrave et al., 1995), and specifically in university students (Aertgeerts et al., 2000; Fleming et al., 1991).

The exclusion criteria were as follows: score higher than 90 in the Global Severity Index (GSI) of the SCL-90-R, or in at least 2 of the symptomatic dimensions, personal history of neurological illness or a relevant systemic, habitual consumption of cannabis or illegal drugs other than alcohol, alcohol or drug consumption 24 hours before the evaluation, personal and / or family history of major mental disorder and history of alcoholism in first-degree relatives, and alcohol abuse / 
dependence, according to the DSM-IV criteria. This procedure was used in an attempt to control possible sources of confusion (such as psychiatric comorbidity or genetic vulnerability) (Cadaveira, 2009).

Sporadic cannabis users were not excluded from the study. A high correlation between alcohol and cannabis use in adolescents and in university students has been consistently reported (Chun et al., 2010; Degenhardt et al., 2001; Falk et al., 2008). Similarly, in the present study, the percentage of cannabis users was significantly higher in the BD group than in the non-BD group.

Finally, once those students who did not meet the requirements and those who decided that they did not wish to continue with the study were excluded from the study, 122 participants were selected: 62 binge drinkers (30 women) and 60 nonbinge drinkers (29 women). The sociodemographic, clinical, and alcohol use pattern characteristics are shown in Table 1.

\section{Table 1}

The selected sample is homogeneous in terms of age, $\mathrm{F}(3,118)=2.06, \mathrm{p}=0.153$; hand dominance, $\mathrm{x}^{2}(1)=0.18, \mathrm{p}=0.664$; socio-economic status, $\mathrm{x}^{2}(1)=3.08, \mathrm{p}=0.543$; GSI of the SCL-90-R, $\mathrm{F}(3,118)=0.02, \mathrm{p}=0.876$; Vocabulary scaled score (Wechsler Adult Intelligence Scale-III [WAIS$\mathrm{III}]), \mathrm{F}(3,118)=2.44, \mathrm{p}=0.121$; and university entrance exam grades, $\mathrm{F}(1,114)=1.55, \mathrm{p}=0.215$.

Binge drinking students consumed alcohol regularly and at a significantly younger age than those in the non-BD group, $\mathrm{F}(1,102)=15.14, \mathrm{p}=0.0001$; they got drunk a significantly greater number of times when they "went out to a party," $\mathrm{F}(1,116)=98.54, \mathrm{p}=0.0001$, and they drank more drinks per hour, $\mathrm{F}(1,116)=165.95, \mathrm{p}=0.0001$. The BD group also scored higher in the AUDIT, $\mathrm{F}(1,102)$ $=236.98, \mathrm{p}=0.0001$.

Participants were asked to abstain from consuming drugs and alcohol for 24 hours before the assessment. All of the individuals signed an informed consent form and received 15 Euros as a bonus for their participation in the study. Psychologist specialists in neuropsychology, blind to the participants' condition, conducted the assessment. 


\section{Material}

Verbal Declarative Memory. The Rey Auditory Verbal Learning Test (RAVLT) (Rey, 1964) involves learning a list of 15 words. The task begins with a reading of a list (list A) that is presented 5 consecutive times; the subject is asked to say all the words that he/she can remember, regardless of the order, after each reading (trials I to V). After the fifth trial, an interference list (list B) is presented, and free recall is requested, after which the subjects are asked to freely recall from list A (trial VI). Thirty minutes later, they are administered a delayed recall trial (trial VII) and then a recognition task consisting of a series of 50 items formed by the words from both lists and other phonologically or semantically similar words. The following data were recorded: the total number of list A words recalled across trials I to V (Total A); the total number of words recalled from list B (Total B); the number of words in the immediate recall of list A (A VI); the number of words recalled after a delay (A VII); the number of words recognized from list A; and the number of perseverations (total number of repetitions of a word previously mentioned during the test), the proactive interference score (difference between the number of words recalled after the first presentation of list A and list B), and the retroactive interference (difference between the number of words recalled in the trial $\mathrm{V}$ and the number recalled in the trial VI of list $\mathrm{A}$ ).

The Logical Memory subtest (Wechsler Memory Scale-III, WMS-III) (Wechsler, 1997a) is a task in which the subject is read 2 brief stories (A and B), with a second presentation of story B. After presentation of each story, the subject is asked to reproduce it as exactly as possible. After 30 minutes, the students are asked to say what they remembered. The participants were then given a recognition test (15 true or false questions per story). The following were then recorded: score for immediate recall (sum of the score for recall of story A and the 2 presentations of story $\mathrm{B}$, for both the thematic units and the themes); the score for the delayed recall (delayed recall of story A plus delayed recall of story $\mathrm{B}$, for both the thematic units and the themes); percentage retention of information (total score for recall of the thematic units in the delayed recall divided by the sum of the scores for recall of thematic units in the immediate recall of story A and the second presentation of story B, expressed as a percentage), and the score for recognition.

Visual Declarative Memory. The Family Pictures subtest (WMS-III) (Wechsler, 1997a) is a task in which the subjects are asked to remember as much information as possible from 4 images (presented consecutively and for 10 seconds each). In each image, different family members (grandfather, grandmother, mother, son, daughter, dog) appear in different situations (snacking, large stores, garden, and lunch). At the end of the presentation of the images, the subject is asked 
which family members were in each of the images, what they were doing and in what location they were situated. The same questions are then asked again after an interval of 30 minutes. The scores for immediate recall, delayed recall, and percentage retention (delayed recall divided by immediate recall, expressed as a percentage) were recorded.

In addition to these tests, the Vocabulary subtest of the WAIS-III was used to estimate the intellectual level of the participants (Wechsler, 1997b) (Table 1).

\section{Data Analysis}

The association between BD pattern, sex of participant, and neuropsychological performance was analyzed by analysis of variance (ANOVA), with Pattern of Consumption (BD and non-BD) by sex. Linear multiple regression was used to analyze the contribution of confounding variables in the performance of those tasks in which differences were observed in the ANOVAs. Estimated intellectual level (Vocabulary scaled score), consumption of cannabis, and age of drinking onset were considered potential confounders variables. Maximal models were generated including all theoretical covariables when these showed $\mathrm{p}<0.2$ in bivariate analysis. From these maximal models, final multiple models were generated. The final multiple models included all significant variables $(\mathrm{p}<0.05)$, and also no significant variables when their exclusion changed the coefficient of main independent variable by more than $10 \%$ (Kleinbaum et al., 1982; Mietten, 1974; Rothman, 1986).

Differences were considered statistically significant at $\mathrm{p}<0.05$. The data were analyzed by use of the SPSS statistics package for Windows, version 15.0 (SPSS Advanced Statistics; SPSS Inc., Chicago IL).

\section{Results}

\section{Binge Drinking by Sex}

There were no significant interaction effects between any of the measures of verbal or visual memory considered and sex of the participant. 


\section{Binge Drinking}

Verbal Memory (RAVLT). The results (Table 2) showed that the Pattern of Alcohol Consumption had a significant effect on the recall of list $\mathrm{B}, \mathrm{F}(1,116)=5.59, \mathrm{p}=0.020$, with the $\mathrm{BD}$ students recalling fewer words than the non-BD subjects. And in the proactive interference index (A1-B), $\mathrm{F}(1,116)=7,14, \mathrm{p}=0.009$, with greater interference observed in BD students than in non-BD subjects. No differences were observed between groups in any of the variables associated with list A.

\section{Table 2}

Logical Memory (WMS-III). The analysis revealed significant differences between groups in terms of their Pattern of Alcohol Consumption in immediate and delayed recall of thematic units, $\mathrm{F}(1,118)=7.11, \mathrm{p}=0.009$ and $\mathrm{F}(1,118)=8.55, \mathrm{p}=0.004$, respectively, and of the themes, $\mathrm{F}(1,118)$ $=6.23, \mathrm{p}=0.014$ and $\mathrm{F}(1,118)=7.55, \mathrm{p}=0.007$, respectively. BD subjects displayed poorer recall of the verbal material presented. Moreover, the percentage retention of the recalled information was lower in the binge drinkers than in the nonbinge drinkers, $F(1,118)=4.21, p=0.042$ (Table 2).

Visual Memory. Family Pictures (WMS-III). The analyses conducted did not reveal any significant differences between the groups in relation to the Pattern of Alcohol Consumption in the variables considered (Table 2).

\section{$\operatorname{Sex}$}

Significant sex differences were observed in total recall of list $\mathrm{A}, \mathrm{F}(1,116)=12.18, \mathrm{p}=0.001$, immediate recall of list $\mathrm{A}, \mathrm{F}(1,166)=8.77, \mathrm{p}=0.004$, delayed recall of list $\mathrm{A}, \mathrm{F}(1,116)=6.000, \mathrm{p}=$ 0.016 , proactive interference, $\mathrm{F}(1,116)=3.92, \mathrm{p}=0.050$, and retroactive interference, $\mathrm{F}(1,116)=$ $8.74, p=0.016$, in the RAVLT. Significant sex differences between the groups were also observed in the immediate and delayed recall of thematic units, $\mathrm{F}(1,118)=4.91, \mathrm{p}=0.029$ and $\mathrm{F}(1,118)=$ $14.45, \mathrm{p}=0.0001$, respectively, and of the themes, $\mathrm{F}(1,118)=6.44, \mathrm{p}=0.012$ and $\mathrm{F}(1,118)=4.11$, $\mathrm{p}=0.045$, respectively, in the Logical Memory subtest. The female students obtained higher scores than the male students for all variables considered, with the exception of proactive interference from the RAVLT task. 


\section{Neuropsychological Performance Predictors}

As shown in Table 3, the BD pattern of consumption is associated with the declarative memory performance after adjusting for the potential confounders (Vocabulary scaled score, Cannabis consumption, and Age onset of drinking). Occasional cannabis consumption did not appear to affect the results.

\section{Discussion}

The main objective of the present study was to determine the association between $\mathrm{BD}$ and declarative memory, which depends mainly on the integrity of the medial temporal lobe, in young university students who do not demonstrate any additional risk factor (such as psychiatric comorbidity, family history of alcoholism, or polysubstance abuse). The study also examined whether female BDs are more vulnerable to the neurotoxic effects of alcohol than male BDs.

In relation to the effect of the pattern of alcohol consumption on declarative memory, the present data show that the BD students demonstrated a significantly lower recall of the contextualized verbal material in the Logical Memory subtest than the non-BD students. Differences in performance were observed both in the immediate and delayed recall. In addition, BD affected the recall of general information (themes), as well as recall of specific or detailed information (thematic units). The Logical Memory subtest of WMS-III has been shown to be dependent on the functioning of the hippocampus, specifically the left hippocampus (Chelune and Bornstein, 1990; Delaney et al., 1980; Moore and Baker, 1996). Moreover, this task is described as the "purest" measure of episodic memory relative to word list-learning task and visuospatial memory tasks, because of its relatively low association with nonmemory measures (Lezak et al., 2004). The poorer verbal episodic declarative memory of the $\mathrm{BD}$ students is consistent with the particular vulnerability of the adolescent hippocampus to the neurotoxic effects of alcohol, which has been shown in both animal studies (Chin et al., 2010; Pascual et al., 2007; White and Swartzwelder, 2005) and human studies (Brown et al., 2000; Medina et al., 2007; Nagel et al., 2005).

The performance differences in the Logical Memory subtest are in contrast with the results obtained in the RAVLT, a task in which prefrontal cortex is involved actively (Alexander et al., 2009; Torres et al., 2001). In this task, both groups obtained similar scores in immediate and delayed recall of list A. However, the BD subjects showed greater susceptibility to proactive interference, which is 
reflected by poorer recall of list B. The differential performance between list learning and story recall measures may reflect differences in the respective task demands on the encoding process. The Logical memory test is presented in a structured story format that provides contextual cues, thus potentially reducing the need to actively organize the information for learning and recall. On the contrary, the RAVLT is an unstructured word list that requires the implementation of active encoding strategies to achieve a good performance. The finding of greater differences occurred between the groups on story recall than on word list learning is consistent with literature regarding the differential roles of frontal and medial temporal lobes in memory, with the frontal lobe more associated with the acquisition of information, and the medial temporal lobe more associated with memory consolidation. Frontal patients do not show performance differences on story recall, because the learning process itself is not impaired. They exhibit significant memory impairment on tasks involving free recall of word lists, because their difficulties are related to their reduced use of memory strategies to enhance encoding and retrieval (Baldo and Shimamura, 2002). In a study with individuals with amnesic mild cognitive impairment divided into 2 groups based on their executive function, greater differences between groups were observed on RAVLT than on Logical memory. Together, these results support the evidence that RAVLT performance relies on executive function to a greater degree than does the Logical memory.

The lower scores for list B may be related to a poorer ability to inhibit interference from 1 task to another. The resistance to interference is a control mechanism related to executive functioning and depends on the integrity of the prefrontal cortex (Badre and Wagner, 2005; Jimura et al., 2009; Torres et al., 2001).

The present results are consistent with those of Garcí a-Moreno and colleagues (2008, 2009), who reported that BD university students showed more perseverations, intrusions, and false positives than nonbinge drinkers in a word-learning test (similar to the California Verbal Learning Test). The authors attributed the differences to executive difficulties rather than to declarative memory. However, Hartley and colleagues (2004) did not find any differences in performance, between BD and non-BD students, in a verbal learning task consisting of the recall as many words as possible from a list of 36 items after a period of 25 minutes. Discrepancies between the results of these studies may be because of differences in the tests used for memory assessment or to the characteristics of the samples.

These findings are consistent with a functional MRI study in which 12 teenagers were compared with 12 nondrinkers BD (Schweinsburg et al., 2010). The BD group exhibited increased right 
prefrontal and bilateral parietal activation during verbal learning. Moreover, although the non-BD subjects displayed significant activation in the left hippocampus during novel encoding, the BD subjects did not. These results may indicate a greater reliance on alternative systems of memory among BD adolescents. Additionally, increased activation of the right prefrontal cortex may reflect increased effort required to suppress irrelevant information.

Taken together, these results suggest that BD subjects need more neural resources to perform the memory task and that they experience greater difficulty in inhibiting interference from the distractors. Both processes depend on the integrity of the hippocampus and prefrontal cortex, which are maturing during adolescence and have been shown to be vulnerable to the neurotoxic effects of alcohol (Blakemore and Choudhury, 2006; De Bellis et al., 2005; Gogtay et al., 2004; Medina et al., 2008; Moselhy et al., 2001; Sowell et al., 2001).

We did not find any significant differences between the groups in performance of the WMS-III Family Pictures subtest, in relation to declarative visuospatial memory. The BD and non-BD students both displayed an adequate capacity for learning and for retrieval of visuospatial material, both in immediate and delayed forms. These results are not consistent learning and visuospatial memory problems have been observed, both after acute consumption of alcohol and in adolescent rats subjected to a pattern of BD consumption (Li et al., 2002; Markwiese et al., 1998; Pascual et al., 2007; White and Swartzwelder, 2005). In humans, Hartley and colleagues (2004) found slight differences between $\mathrm{BD}$ and non-BD in a visual memory test requiring the recall of as many as possible of 20 line drawings of common objects after a period of 25 minutes.

In contrast to verbal memory tasks, up until now, there is no "pure" test that assesses visuospatial memory. These tests typically require subjects to recall objects, geometric shapes, complex designs, or faces, as well as the spatial locations of the stimuli. This information is frequently amenable to the application of verbal encoding strategies. For this reason, while there is a strong association between verbal memory and left temporal lobe, there is no such clear association between visual memory and right temporal lobe (Chapin et al., 2009; Doss et al., 2004; Silverberg and Buchanan, 2005). As in the case of RAVLT, the fact that in the present study, we did not find any differences between the $\mathrm{BD}$ and non-BD groups in visual memory may be attributed to the use of nonvisuospatial strategies that permitted the subjects to recall the information effectively. An alternative explanation is based on studies conducted on adolescents and young adults with AUD, which have shown that the difficulties in visuospatial memory are associated with symptoms of 
abstinence syndrome (Tapert et al., 2002). In this way, the absence of differences in the present study may be because of the characteristics of the sample.

In terms of the second objective of the study, to determine whether women are more vulnerable to the neurotoxic effects of a BD pattern of consumption than men, no significant differences were observed in the neuropsychological performance of BD men and women, in any of the tasks analyzed. Although the results do not confirm the hypothesis, they are not completely surprising. Studies conducted with adult chronic alcoholics suggest that the greater vulnerability in women does not imply more severe neurocognitive consequences, but that such consequences may be manifested in subjects with shorter drinking histories (Agartz et al., 1999; Hommer, 2003; Hommer et al., 2001; Jacobson, 1986; Mann et al., 1992). Taking into account that studies with adult populations were conducted with alcoholic patients that had been consuming alcohol for more than 10 years, the fact that the history of consumption in the present study was relatively short (an average of 4 years) may explain the absence of differences. This hypothesis may find support in the results of the studies conducted by Duka and colleagues with social drinkers (18 to 30 years old) who consumed alcohol for longer than the subjects in the present study (Scaife and Duka, 2009; Townshend and Duka, 2005; Weissenborn and Duka, 2003). Together, these studies have shown that women social drinkers with a BD pattern of consumption performed significantly worse than men in visuospatial working memory tasks. Studies with AUD adolescents have also found that women are more vulnerable than men to the neurotoxic effects of alcohol (Caldwell et al., 2005; Medina et al., 2008).

In conclusion, the present results showed that the BD pattern of consumption was associated with poorer verbal declarative memory. Specifically, young binge drinkers performed less well in both immediate and delayed memory tasks, which rely on the left medial temporal lobe, and showed greater susceptibility to proactive interference in the RAVLT, which depends on the prefrontal cortex. The poorer performance of the BD group did not appear to be the result of differences between the groups in their estimated general intellectual capabilities, occasional cannabis use, age onset of drinking, family socioeconomic status, family history of alcoholism or psychopathology or polysubstance use, variables that were controlled for during the selection of the sample or through multiple regressions. However, we must be cautious in interpreting this association. Are these neuropsychological differences a consequence of the BD pattern of consumption? Alternatively, are they risk factors? Longitudinal studies are likely to provide the answer to these important questions, which cannot be established in a cross-sectional study. 
In addition, adolescence and early adulthood are critical periods of life in terms of integrating into the adult society, during which activities that require a high level of cognitive competence are required on a daily basis. This makes it important to determine whether differences in performance between the binge drinkers and nonbinge drinkers may have repercussions on academic performance.

There are several limitations to the present study. First, it is a cross-sectional study, so that we were not able to establish a causal relationship between the pattern of alcohol consumption and the different scores obtained. Although we attempted to control several confounding factors, and the samples did not differ in terms of age, educational, socioeconomic, or intellectual ability, it is possible that the differences observed are premorbid, or that they are the result of the effect of other variables not considered in the study. Second, design used did not allow to determine whether the effect is attributable to the amount consumed or to the pattern of consumption. Evaluation of another group of subjects who regularly consume alcohol may help clarify this aspect. Third, the procedure and the strict selection criteria may have led to the exclusion of those young people with a more severe pattern of drinking, so that our sample may not be entirely representative of BD university students. Fourth, because of time limitations, only 1 visual memory test was used. This test was selected because it is a commonly used, standardized test, which facilitates replication and comparison of the results with those of other studies. It is free of motor and visuoconstructive components. And it provides information about immediate recall, delayed recall, retention, and recognition, which enables discrimination between difficulties in coding, consolidation, and recovery. Despite the detailed information provided by the test, it is possible that it does not explore visual memory adequately or with sufficient sensitivity, so that a more exhaustive examination may be required. Finally, as we do not have available structural or functional measures of the participants in the study, we cannot establish anatomical-functional relationships.

These findings raise several questions to be addressed by further research. Longitudinal studies are required to evaluate young subjects before they start consuming alcohol, to clarify the relationship between the pattern of consumption and neuropsycological differences. Moreover, the BD pattern of alcohol consumption tends to decrease with age. Studies with chronic alcoholics indicate the reversibility of brain damage in response to abstinence. It would be interesting to follow up the young subjects who participated in the present study, to determine whether abandonment of the BD pattern of alcohol consumption is associated with changes in neuropsychological parameters. If so, we would obtain further evidence for a causal relationship. Finally, future studies should determine 
whether the significant differences observed in the study are associated with poorer academic performance.

\section{Acnowledgments}

This research was supported by Consellería de Innovación e Industria of Xunta de Galicia, grant number PGI-DIT05CS021103PR and INCITE08PXIB211015PR, by Plan Nacional sobre Drogas of Ministerio de Salud y Consumo of Spain, grant number 2005/PN014, and by Ministerio de Ciencia e Innovación of Spain, grant number EDU2008-03440.

\section{References}

Acker C (1986) Neuropsychological deficits in alcoholics: the relative contributions of gender and drinking history. Br J Addict 81:395-403.

Aertgeerts B, Buntinxs F, Ansoms S, Fevery J (2000) The value of CAGE, CUGE and AUDIT in screening for alcohol abuse and dependence among college freshmen. Alcohol Clin Exp Res 24:53-57.

Agartz I, Momenan R, Rawlings RR, Kench MJ, Hommer DW (1999) Hippocampal volume in patients with alcohol dependence. Arch Gen Psychiatry 56:356-363.

Alexander MP, Stuss D, Gillingham S (2009) Impaired list learning is not a general property of frontal lesions. J Cogn Neurosci 21:1422-1434.

Allen JP, Litten RZ, Fertig JB, Babor T (1997) A review of research on the Alcohol Use Disorders Identification Test (AUDIT). Alcohol Clin Exp Res 31:1589-1597.

Anderson P (2007) Binge Drinking and Europe. Institute of Alcohol Studies, London.

Babor TF, Higgins-Biddle JC, Saunders JB, Monteiro MG (2001) AUDIT. The Alcohol Use Disorders Identification Test. Guidelines for Use in Primary Health Care. 2nd ed. World Health Organization, Geneva.

Badre D, Wagner AD (2005) Frontal lobe mechanisms that resolve proactive interference. Cereb Cortex 15:2003-2012.

Baldo JV, Shimamura AP (2002) Frontal lobes and memory, in The Handbook of Memory Disorders. 2nd ed. (Baddeley AD, Kopelman MD, Wilson BA eds) pp. 363-380. Wiley \& Sons Inc., London.

Blakemore SJ, Choudhury S (2006) Development of the adolescent brain: implications for executive function and social cognition. J Child Psychol Psychiatry 47:296-312.

Brown SA, Tapert S, Granholm E, Delis DC (2000) Neurocognitive functioning of adolescents: effects of protracted alcohol use. Alcohol Clin Exp Res 24:164-171. 
Bucholz KK, Cadoret R, Cloninger CR, Dinwiddie SH, Hesselbrock VM, Nurnberger JI, Reich T, Schmidt I, Schuckit MA (1994) A new semi-structured psychiatric interview for use in genetic linkage studies: a report of the reliability of the SSAGA. J Stud Alcohol 55:149158.

Burgess N, Maguine EA, O'Keefe J (2002) The human hippocampus and spatial and episodic memory. Neuron 35:625-641.

Caamañ o-Isorna F, Corral M, Parada M, Cadaveira F (2008) Factors associated with risky consumption and heavy episodic drinking among spanish university students. J Stud on Alcohol Drugs 69:308-312.

Cadaveira F (2009) Alcohol y cerebro adolescente. Adicciones 21:9-14. Caldwell LC, Schweinsburg AD, Nagel BJ, Barlett VC, Brown SA, Tapert SF

(2005) Gender and adolescent alcohol use disorders on BOLD (blood oxygen level dependent) response to spatial working memory. Alcohol Alcohol 40:194-200.

Chapin JS, Busch RM, Naugle RI, Najm IM (2009) The Family Pictures subtest of the WMS-III: relationship to verbal and visual memory following temporal lobectomy for intractable epilepsy. J Clin Exp Neuropsychol 31:498-504.

Chelune GJ, Bornstein RA (1990) WMS-R patterns among patients with unilateral brain lesions. Clin Neuropsychol 2:121-132.

Chin VS, Van Skike CE, Matthews DB (2010) Effects of ethanol on hippocampal function during adolescence: a look at the past and thoughts on the future. Alcohol 44:3-14.

Chun TH, Spirito A, Herná ndez L, Fairlie AM, Sindelar-Manning H, Eaton CA, Lewander WS (2010) The significance of marijuana use among alcohol-using adolescent emergency department patients. Academ Emerg Med 17:63-71.

Conigrave KM, Hall WD, Saunders JB (1995) The AUDIT questionnaire: choosing a cut-off score. Addiction 90:1349-1356.

Courtney KE, Polich J (2009) Binge drinking in young adults: data, definitions, and determinants. Psychol Bull 135:142-156.

Crego A, Rodríguez Holguín S, Parada M, Mota N, Corral M, Cadaveira F (2010) Reduced anterior prefrontal cortex activation in young binge drinkers during a visual working memory task. Drug Alcohol Depend 109:45-56.

Crews FT, He J, Hodge C (2007) Adolescent cortical development: a critical period of vulnerability for addiction. Pharmacol Biochem Behav 86:189-199.

De Bellis MD, Clark DB, Beers SR, Soloff PH, Boring AM, Hall J, Kersh A, Keshavan MS (2000) Hippocampal volume in adolescent-onset alcohol use disorders. Am J Psychiatry 157:737744.

De Bellis MD, Narasimhan A, Thatcher DL, Keshavan MS, Soloff P, Clark DB (2005) Prefrontal cortex, thalamus, and cerebellar volumes in adolescents and young adults with adolescentonset alcohol use disorders and comorbid mental disorders. Alcohol Clin Exp Res 29:15901600 .

Degenhardt L, Hall W, Lynskey M (2001) The relationship between cannabis use and other substance use in the general population. Drug Alcohol Depend 64:319-327. 
Degoratis LR (1983) SCL-90-R. Administration, Scoring and Procedures Manual II for the Revised Version of the SCL-90. John Hopkins University Press, Baltimore.

Delaney RC, Rosen AJ, Mattson RH, Novelly RA (1980) Memory function in focal epilepsy: a comparison of non-surgical, unilateral temporal lobe and frontal lobe samples. Cortex 16:103-117.

Department of Health and Human Services (2002) High-riskdrinking in college: what we know and what we need to learn. Available at: http//www. collegedrinkingprevention.gov/NIAAACollegeMaterials/pane101/Panel01__ TOC.aspx. Accessed January 8, 2009.

Doss RC, Chelune GJ, Naugle RI (2004) WMS-III performance in epilepsy patients following temporal lobectomy. J Int Neuropsychol Soc 10:173-179.

Eichenbaum H (1999) The hippocampus and mechanisms of declarative memory. Behav Brain Res 103:123-133.

Eurobarometer (2007) Attitudes towards alcohol. June 4. Available at: http://ec.europa.eu/public_opinion/archives/ebs/ebs_272b_en.pdf. Accessed January 26, 2010.

Falk D, Yi H, Hiller-Sturmho“ fel S (2008) An epidemiological analysis of cooccurring alcohol and drug use and disorders. Findings from the national epidemiologic survey of alcohol and related conditions (NESARC). Alcohol Res Health 31:100-110.

Fleming MF, Barry KL, MacDonald R (1991) The alcohol use disorders identification test (AUDIT) in a college sample. Int J Addict 26:1173-1185.

García-Moreno LM, Expósito J, Sanhueza C, Angulo MT (2008) Actividad prefrontal y alcoholismo de fin de semana en jo’ venes. Adicciones 20:271-279.

García-Moreno LM, Expósito J, Sanhueza C, Gil S (2009) Rendimiento cognitivo y consumo de alcohol durante los fines de semana en mujeres adolescentes. Neuropsicol, Neuropsiquiatr Neuroci 19:75-91.

Glenn SW, Parsons OA (1992) Neuropsychological efficiency measures in male and female alcoholics. J Stud Alcohol 53:546-552.

Gogtay N, Giedd JM, Lusk L, Hayashi KM, Greenstein D, Vaituzis AC, Nugent TF, Herman DH, Clasen LS, Toga AW, Rapopport JL, Thompson PM (2004) Dynamic mapping of human cortical development during childhood through early adulthood. Proc Natl Acad Sci USA 101:8174-8179.

Guerri C, Pascual M (2010) Mechanisms involved in the neurotoxic, cognitive, and neurobehavioral effects of alcohol consumption during adolescence. Alcohol 44:15-26.

Hartley DE, Elsabagh S, File SE (2004) Binge drinking and sex: effects on mood and cognitive function in healthy young volunteers. Pharmacol Biochem Behav 78:611-619.

Hibell B, Andersson B, Bjarnason T, Ahlstrom S, Balakireva O, Koklevi A, Morgan M (2004) The ESPAD Report 2003, Alcohol and Other Drugs use Among Students in 35 European Countries. The Swedish council for information on alcohol and other drugs (CAN) and the Pompidou Group at the council of Europe, Stockholm.

Hommer DW (2003) Male and female sensitivity to alcohol-induced brain damage. Alcohol Res Health 27:181-185. 
Hommer DW, Momenan R, Kaiser E, Rawlings RR (2001) Evidence for a gender-related effect of alcoholism on brain volumes. Am J Psychiatry 158:198-204.

International Center for Alcohol Policies (2003) ICAP blue book. Practical guide for alcohol policy and prevention approaches. June 28. Available at: http:// www.icap.org/PolicyTools/ICAPBlueBook/BlueBookModules/20Standard Drinks/tabid/161/Default.aspx. Accessed January 4, 2010.

Jacobson R (1986) The contributions of sex and drinking history to the CT brain scan changes in alcoholics. Psychol Med 16:547-559.

Jimura K, Yamashita K, Chikazoe J, Hirose S, Miyashita Y, Konishi S (2009) A critical component that activates the left inferior prefrontal cortex during interference resolution. Eur $\mathbf{J}$ Neurosci 29:1915-1920.

Kleinbaum DG, Kupper LL, Morgenstern H (1982) Epidemiologic Research. Principles and Quantitative Methods. Van Nostrand Reinhold, New York.

Kypri K, Paschall MJ, Langley J, Baxter J, Cashel-Smith M, Bourdeau B (2009) Drinking and alcohol-related harm among New Zealand university students: findings from a national Web-based survey. Alcohol Clin Exp Res 33:307-314.

Lenroot RK, Giedd JN (2006) Brain development in children and adolescents: insights from anatomical magnetic resonance imaging. Neurosci Biobehav Rev 30:718-729.

Lezak M, Howieson DB, Lonng DW, Hanna HJ, Fischer JJ (2004) Neuropsychological Assessment. 4th ed. Oxford University Press, New York.

Li Q, Wilson WA, Swartzwelder HS (2002) Differential effect of ethanol on NMDA EPSCs in pyramidal cells in the posterior cingulate cortex of juvenile and adult rats. J Neurophysiol 87:705-711.

Mann K, Ackermann K, Croissant B, Mundle G, Nakovics H, Diehl A (2005) Neuroimaging of gender differences in alcohol dependence: are women more vulnerable? Alcohol Clin Exp Res 29:896-901.

Mann K, Batra A, Gu“ nthner A, Schroth G (1992) Do women develop alcoholic brain damage more readily than men? Alcohol Clin Exp Res 16:1052-1056.

Markwiese BJ, Acheson SK, Levin ED, Wilson WA, Swartzwelder HS (1998) Differential effects of ethanol on memory in adolescent and adult rats. Alcohol Clin Exp Res 22:416-421.

Medina KL, McQueeny T, Nagel BJ, Hanson KL, Schweinsburg AD, Tapert SF (2008) Prefrontal cortex volumes in adolescents with alcohol use disorders: unique gender effects. Alcohol Clin Exp Res 32:386-394.

Medina KL, Schweinsburg AD, Cohen-Zion M, Nagel BJ, Tapert SF (2007) Effects of alcohol and combined marijuana and alcohol use during adolescence on hippocampal volume and asymmetry. Neurotoxicol Teratol 29:141-152.

Mietten OS (1974) Confounding and effect-modification. Am J Epidem 100:350-353.

Moore PM, Baker GA (1996) Validation of the Wechsler Memory Scale-Revised in a sample of people with intractable temporal lobe epilepsy. Epilepsia 37:1215-1220.

Moselhy HF, Georgiou G, Kahn A (2001) Frontal lobe changes in alcoholism: a review of the literature. Alcohol Alcohol 36:357-368. 
Mota N, Álvarez-Gil R, Corral M, Rodríguez Holguín S, Parada M, Crego A, Caamaño-Isorna F, Cadaveira F (2010) Risky alcohol use and heavy episodic drinking among Spanish university students: a two-year follow-up. Gac Sanit 24:372-377.

Nagel BJ, Schweinsburg AD, Phan V, Tapert SF (2005) Reduced hippocampal volume among adolescents with alcohol use disorders without psychiatric comorbidity. Psychiatry Res 139:181-190.

O’Malley PM, Bachman JG, Johnston LD (1984) Period, Age, and Cohort Effects on Substance Use Among American Youth 1976-1982. Institute for Social Research, Michigan.

Oscar-Berman M, Marinkovic K (2007) Alcohol: effects on neurobehavioral functions and the brain. Neuropsychol Rev 17:239-257.

Pascual M, Blanco AM, Cauli O, Minarro J, Guerri C (2007) Intermittent ethanol exposure induces inflammatory brain damage and causes long-term behavioural alterations in adolescent rats. Eur J Neurosci 25:541-550.

Pyapali GK, Turner DA, Wilson WA, Swartzwelder HS (1999) Age and dose-dependent effects of ethanol on the induction of hippocampal long-term potentiation. Alcohol 19:107-111.

Rey A (1964) L'examen clinique en psychologie. Presses Universitaires de France, Paris.

Rothman KJ (1986) Modern Epidemiology. Little Brown, Boston.

Scaife JC, Duka T (2009) Behavioural measures of frontal lobe function in a population of young social drinkers with binge drinking pattern. Pharmacol Biochem Behav 93:354-362.

Schulteis G, Archer C, Tapert SF, Frank LR (2008) Intermittent binge alcohol exposure during the periadolescent period induces spatial working memory deficits in young adult rats. Alcohol 42:459-467.

Schweinsburg AD, McQueeny T, Nagel BJ, Eyler LT, Tapert SF (2010) A preliminary study of functional magnetic resonance imaging response during verbal encoding among adolescent binge drinkers. Alcohol 44:111-117.

Sher KJ, Martin ED, Wood PK, Rutledge PC (1997) Alcohol use disorders and neuropsychological functioning in first-year undergraduates. Exp Clin Psychopharmacol 5:304-315.

Silverberg N, Buchanan L (2005) Verbal mediation and memory for novel figural designs: a dual interference study. Brain Cogn 57:198-209.

Sowell ER, Thompson PM, Tessner KD, Toga AW (2001) Mapping continued brain growth and gray matter density reduction in dorsal frontal cortex: inverse relationships during postadolescent brain maturation. J Neurosci 21:8819-8829.

Spear LP (2000) The adolescent brain and age-related behavioral manifestations. Neurosci Biobehav Rev 2000:417-463.

Swartzwelder HS, Wilson WA, Tayyeb MI (1995a) Age-dependent inhibition of long-term potentiation by ethanol in immature versus mature hippocampus. Alcohol Clin Exp Res 19:1480-1485.

Swartzwelder HS, Wilson WA, Tayyeb MI (1995b) Differential sensitivity of NMDA receptormediated synaptic potentials to ethanol in immature versus mature hippocampus. Alcohol Clin Exp Res 19:320-323. 
Taffe MA, Kotzebue RW, Crean RD, Crawford EF, Edwards S, Mandyam CD (2010) Long-lasting reduction in hippocampal neurogenesis by alcohol consumption in adolescent nonhuman primates. Proc Natl Acad Sci USA 107:11104-11109.

Tapert SF, Baratta MV, Abrantes AM, Brown SA (2002) Attention dysfunction predicts substance involvement in community youths. J Am Acad Child Adolesc Psychiatry 41:680-686.

Tapert SF, Brown SA (1999) Neuropsychological correlates of adolescent substance abuse: fouryear outcomes. J Int Neuropsychol Soc 5:481-493.

Teyler TJ, Rudy JW (2007) The hippocampal indexing theory and episodic memory: updating the index. Hippocampus 17:1158-1169.

Torres IJ, Flashman LH, O'Leary DS, Andreasen NC (2001) Effects of retroactive and proactive interference on word list recall in schizophrenia. J Int Neuropsychol Soc 7:481-490.

Townshend JM, Duka T (2005) Binge drinking, cognitive performance and mood in a population of young social drinkers. Alcohol Clin Exp Res 29:317-325.

Van Petten C (2004) Relationship between hippocampal volume and memory ability in healthy individuals across the lifespan: review and meta-analysis. Neuropsychologia 42:13941413.

Varela J, Braña T, Real E, Rial A (2005) Validación empírica do AUDIT (Cuestionario de Identificación dos Trastornos debido ó consumo de alcohol) na poboación xeral galega. Xunta de Galicia, Consellería de Sanidade-SERGAS, Santiago de Compostela.

Wechsler D (1997a) Wechsler Memory Scale-III. The Psychological Corporation, San Antonio.

Wechsler D (1997b) Wechsler Adult Intelligence Scale-III. The Psychological Corporation, San Antonio.

Wechsler H, Lee JE, Kuo M, Seibring M, Nelson TF, Lee H (2002) Trends in college binge drinking during a period of increased prevention efforts. Findings from 4 Harvard School of Public Health College Alcohol Study surveys: 1993-2001. J Am Coll Health 50:203217.

Weissenborn R, Duka T (2003) Acute alcohol effects on cognitive function in social drinkers: their relationship to drinking habits. Psychopharmacology 165:306-312.

White AM, Ghia AJ, Levin ED, Swartzwelder HS (2000) Binge pattern ethanol exposure in adolescent and adult rats: differential impact on subsequent responsiveness to ethanol. Alcohol Clin Exp Res 24:1251-1256.

White AM, Kraus CL, Swartwelder HS (2006) Many college freshmen drink at levels far beyond the binge threshold. Alcohol Clin Exp Res 30:1006-1010.

White AM, Swartzwelder HS (2004) Hippocampal function during adolescence: a unique target of ethanol effects. Ann N Y Acad Sci 1021:206-220.

White AM, Swartzwelder HS (2005) Age-related effects of alcohol on memory and memory-related brain function in adolescents and adults, in Recent Developments in Alcoholism, Vol. 17, Alcohol Problems in Adolescents and Young Adults (Lowman C, Boyd GM, Fader VB, Witt E eds), pp. 161-178. Kluwer Academic/Plenum Publishers, New York.

Yonker JE, Nilsson LG, Herlitz A, Antherzelli RM (2005) Sex differences in spatial visualization and episodic memory as a function of alcohol consumption. Alcohol Alcohol 40:201-207. 
Yurgelun-Todd DA (2007) Emotional and cognitive changes during adolescence. Curr Opin Neurobiol 17:251-257. 
Table 1. Sociodemographic, clinical, and alcohol use characteristics of the sample

\begin{tabular}{lllll}
\hline & \multicolumn{2}{c}{ No BD } & \multicolumn{1}{c}{ BD } \\
\cline { 2 - 5 } & \multicolumn{1}{c}{ Men } & \multicolumn{1}{c}{ Women } & \multicolumn{1}{c}{ Women } \\
\hline N & 31 & 29 & 32 & 30 \\
Age & $18.61(0.55)$ & $18.83(0.53)$ & $19.03(0.53)$ & $18.70(0.59)$ \\
Hand-dominance (right/left) & $28 / 3$ & $28 / 1$ & $31 / 1$ & $28 / 2$ \\
Socioeconomic status (low/medium/high) & $0 / 27 / 4$ & $4 / 22 / 3$ & $2 / 27 / 3$ & $3 / 19 / 7$ \\
Caucasian ethnicity (\%) & 100 & 100 & 100 & 100 \\
SCL-90-R (percentile GSI) & $55.00(28.83)$ & $41.72(25.57)$ & $60.50(31.86)$ & $37.83(26.96)$ \\
Vocabulary scaled score (WAIS-III) & $12.65(2.27)$ & $12.52(1.74)$ & $12.59(1.43)$ & $11.57(1.50)$ \\
University entrance exam grades & $6.59(1.17)$ & $6.63(0.82)$ & $6.38(1.27)$ & $6.31(1.20)$ \\
Tobacco smokers & 0 & 1 & 4 & 8 \\
Occasional use of cannabis & & & 14 & 13 \\
Age of drinking onset* & 2 & 7 & $15.13(1.26)$ & $14.53(1.26)$ \\
Percentage of times became drunk when & $16.00(0.85)$ & $15.54(1.25)$ & $51.18(31.04)$ & $49.00(34.72)$ \\
drinking* & $5.39(11.62)$ & $5.96(7.78)$ & & \\
Speed of consumption: drinks per hour* & & & $3.41(1.38)$ & $3.29(0.76)$ \\
Total AUDIT score* & $0.65(0.87)$ & $1.14(0.99)$ & $12.91(4.72)$ & $11.47(4.04)$ \\
\hline
\end{tabular}

Data are number of subjects, mean (SD) or percentage. SCL-90-R, Symptom Checklist 90 Revised; GSI, Global Severity Index; WAIS-III, Wechsler Adult Intelligence Scale-III; AUDIT, Alcohol Use Disorders Identification Test; $\mathrm{BD}$, binge drinking.

$* p<0.001$ significant BD differences.

a $<10$ occasions per year. 
Table 2. Mean (SD) scores obtained in verbal and visual declarative memory tasks

\begin{tabular}{|c|c|c|c|c|}
\hline & \multicolumn{2}{|c|}{ No BD } & \multicolumn{2}{|c|}{ BD } \\
\hline & $\operatorname{Men}(n=31)$ & Women $(n=29)$ & $\operatorname{Men}(n=32)$ & Women $(\mathbf{n}=\mathbf{3 0})$ \\
\hline \multicolumn{5}{|l|}{ RAVLT } \\
\hline Total A (max. 75) & $59.27(5.31)$ & $62.39(4.84)$ & $58.81(5.25)$ & $62.33(5.37)$ \\
\hline Total B (max. 15)* & $7.73(2.31)$ & $7.96(2.16)$ & $6.75(1.43)$ & $7.20(2.09)$ \\
\hline A VI (inmediate recall) (max. 15$)$ & $12.97(1.52)$ & $13.96(1.17)$ & $12.63(2.12)$ & $13.43(1.65)$ \\
\hline A VII (delayed recall) (max. 15) & $13.03(1.49)$ & $14.07(1.05)$ & $13.09(1.65)$ & $13.37(1.54)$ \\
\hline Recognition A (max. 15) & $14.50(0.68)$ & $14.79(0.41)$ & $14.66(0.54)$ & $14.67(0.54)$ \\
\hline Proactive interference $(\mathrm{A} 1-\mathrm{B})^{* *}$ & $-0.30(2.21)$ & $0.82(2.14)$ & $1.09(1.71)$ & $1.53(2.50)$ \\
\hline Retroactive interference (AV-AVI) & $1.10(1.39)$ & $0.50(0.74)$ & $1.47(1.79)$ & $0.63(1.06)$ \\
\hline Perseverations & $4.60(4.51)$ & $4.36(3.75)$ & $5.66(5.36)$ & $4.83(4.69)$ \\
\hline Intrusions & $0.80(1.03)$ & $0.71(0.81)$ & $0.72(1.02)$ & $0.97(1.09)$ \\
\hline \multicolumn{5}{|l|}{ Logical memory (WMS-III) } \\
\hline Thematic units inmediate recall $(\max .75) * *$ & $52.81(7.49)$ & $56.76(5.99)$ & $50.53(7.24)$ & $52.23(7.24)$ \\
\hline Themes inmediate recall $(\max .21) *$ & $15.87(1.87)$ & $17.48(1.82)$ & $15.25(2.06)$ & $16.33(2.04)$ \\
\hline Thematic units delayed recall $(\max .50)^{* *}$ & $34.13(4.65)$ & $36.90(4.28)$ & $31.78(6.02)$ & $33.77(5.45)$ \\
\hline Themes delayed recall $(\max .14)^{* * *}$ & $10.18(1.54)$ & $11.24(1.12)$ & $10.03(1.51)$ & $10.33(1.58)$ \\
\hline Percent retention* & $92.81(6.95)$ & $93.79(5.90)$ & $89.44(9.77)$ & $91.60(6.45)$ \\
\hline Recognition (max. 30) & $27.87(1.56)$ & $28.10(1.76)$ & $27.53(2.06)$ & $28.03(1.35)$ \\
\hline \multicolumn{5}{|l|}{ Family pictures (WMS-III) } \\
\hline Total inmediate recall (max. 64) & $46.39(7.84)$ & $50.97(7.47)$ & $47.72(9.75)$ & $48.55(7.15)$ \\
\hline Total delayed recall (max. 64) & $46.26(8.12)$ & $51.17(7.57)$ & $48.19(9.14)$ & $48.17(8.13)$ \\
\hline Percent retention & $99.65(5.16)$ & $100.38(1.72)$ & $101.53(9.07)$ & $98.55(4.33)$ \\
\hline
\end{tabular}

RAVLT, Rey Auditory Verbal Learning Test; WMS-III, Wechsler Memory Scale-III; BD, binge drinking.

$* p<0.05$ significant differences, $* * p<0.01$ significant differences 
Table 3. Multiple Linear Regression Analysis of Predictors of the Performance on Memory Tasks

\begin{tabular}{|c|c|c|c|c|c|c|c|c|c|c|c|c|c|}
\hline & \multicolumn{4}{|c|}{ Rey Auditory Verbal Learning Test } & \multicolumn{6}{|c|}{ Logical memory I } & \multicolumn{3}{|c|}{ Logical memory II } \\
\hline & \multicolumn{2}{|l|}{ Total B } & \multicolumn{2}{|c|}{$\begin{array}{l}\text { Proactive } \\
\text { interference }\end{array}$} & \multicolumn{2}{|c|}{$\begin{array}{l}\text { Units inmediate } \\
\text { recall }\end{array}$} & \multicolumn{2}{|c|}{$\begin{array}{l}\text { Themes inmediate } \\
\text { recall }\end{array}$} & \multicolumn{2}{|c|}{ Units delayed recall } & \multicolumn{2}{|c|}{$\begin{array}{l}\text { Themes delayed } \\
\text { recall }\end{array}$} & \multirow{2}{*}{$\begin{array}{l}\begin{array}{l}\text { Percen } \\
\text { reten- } \\
\text { tion }\end{array} \\
\begin{array}{l}\text { Bivaria } \\
\text {-te B }\end{array}\end{array}$} \\
\hline & $\begin{array}{l}\text { Bivaria } \\
\text {-te B }\end{array}$ & $\begin{array}{l}\text { Multiva } \\
\text {-riate }^{\text {a }} \\
\text { B }\end{array}$ & $\begin{array}{l}\text { Bivaria } \\
\text {-te B }\end{array}$ & $\begin{array}{l}\text { Multivaria } \\
-\operatorname{te}^{\mathrm{a}} B\end{array}$ & $\begin{array}{l}\text { Bivaria } \\
\text {-te B }\end{array}$ & $\begin{array}{l}\text { Multivaria } \\
-\operatorname{te}^{\mathrm{a}} \text { B }\end{array}$ & $\begin{array}{l}\text { Bivaria } \\
\text {-te B }\end{array}$ & $\begin{array}{l}\text { Multivaria } \\
- \text {-te }^{\mathrm{a}} \text { B }\end{array}$ & $\begin{array}{l}\text { Bivaria } \\
-\operatorname{te}^{\mathrm{a}} B\end{array}$ & $\begin{array}{l}\text { Multivaria } \\
- \text {-te }^{\mathrm{a}} \text { B }\end{array}$ & $\begin{array}{l}\text { Bivaria } \\
\text {-te B }\end{array}$ & $\begin{array}{l}\text { Multivaria } \\
- \text {-te }^{\mathrm{a}} \text { B }\end{array}$ & \\
\hline $\begin{array}{l}\text { Binge } \\
\text { drinking }\end{array}$ & $-0.877^{*}$ & $-0.800 *$ & $1.065 * *$ & $1.064 * *$ & $-3.362 *$ & $-2.903^{*}$ & $-0.876^{*}$ & $-0.763^{*}$ & $-{ }^{-} .725^{* *}$ & $-2.340^{*}$ & - $0.689 * *$ & $-0.632 *$ & $-2.799 *$ \\
\hline $\operatorname{Sex}^{\mathrm{c}}$ & 0.343 & & 0.770 & 0.769 & $2.807^{*}$ & $2.674 *$ & $1.343 * *$ & $1.310^{* *}$ & $2.369 *$ & $2.257^{*}$ & 0.510 & 0.493 & 1.583 \\
\hline $\begin{array}{l}\text { Vocabulary } \\
\text { scaled score }\end{array}$ & 0.379 & 0.309 & -0.125 & & $2.012^{*}$ & $1.652 *$ & $0.520^{*}$ & 0.408 & $1.679 * *$ & $1.386^{*}$ & 0.282 & 0.206 & 0.389 \\
\hline $\begin{array}{l}\text { Cannabis } \\
\text { consumption } \\
\text { b }\end{array}$ & 0.313 & & -0.099 & & -0.160 & & -0.172 & & -0.786 & & -0.181 & & -2.758 \\
\hline $\begin{array}{l}\text { Age onset of } \\
\text { drinking }\end{array}$ & 0.014 & & 0.198 & & 0.769 & & $0.671 *$ & & 0.219 & & 0.318 & & -0.661 \\
\hline
\end{tabular}

